\title{
COMUNICAÇÃO COMUNITÁRIA NA POLÍTICA DE COMUNICAÇÃO ORGANIZACIONAL: Protocolo voltado aos territórios, às comunidades e aos modos de vida no Maranhão
}

COMMUNITY COMMUNICATION IN THE ORGANIZATIONAL COMMUNICATION POLICY: Protocol aimed at territories, communities and ways of life in Maranhão

COMUNICACIÓN COMUNITARIA EN LA POLÍTICA DE COMUNICACIÓN ORGANIZACIONAL: Protocolo dirigido a territorios, comunidades y formas de vida en Maranhão

\section{Flávia de Almeida Moura}

Doutora em Comunicação pela PUC-RS (Pontifícia Universidade Católica do Rio Grande do Sul), Mestre em Ciências Sociais pela UFMA (Universidade Federal do Maranhão), professora do Programa de Pós-Graduação em Comunicação - Mestrado Profissional da UFMA (Universidade Federal do Maranhão)

flavia.moura@ufma.br, https://orcid.org/0000$\underline{0002-6672-2319}$

\section{Amarilis Cardoso dos Santos}

Mestranda em Comunicação pelo Programa de Pós-Graduação em Comunicação - Mestrado Profissional da UFMA (Universidade Federal do Maranhão), Graduada em Relações Públicas pela UFMA

amariliscardoso@yahoo.com.br

https://orcid.org/0000-0002-2355-3033

Correspondência: Universidade Federal do Maranhão, Av.dos Portugueses, s / n, Bacanga, São Luís, Maranhão

Recebido em: 16.02.2021.

Aceito em: 16.04 .2021$.

Publicado em: 01.07.2021.

\begin{abstract}
RESUMO
O artigo apresenta parte de uma pesquisa em andamento que visa compreender de que formas a comunicação comunitária se insere na política de comunicação organizacional. $\mathrm{O}$ estudo objetiva apresentar, como produto final, um Protocolo de Comunicação Comunitária voltado aos territórios, às comunidades e aos modos de vida no Maranhão; um método de correlação entre a teoria e a prática a partir das particularidades desse território, para assim, tornar-se uma possibilidade do mercado adotar e reaplicar. A principal metodologia utilizada é o design science (DS) como um caminho possível à pesquisa aplicada em Comunicação (SANTOS, 2018). O trabalho tem o intuito de contribuir com a área de Comunicação Comunitária ao se propor deixar um Protocolo como contribuição à ação da prática profissional a partir da realidade local.
\end{abstract}

PALAVRAS-CHAVE: Comunicação Organizacional; Comunicação Comunitária; Protocolo.

\section{Introdução}

Este artigo apresenta parte da pesquisa em andamento que busca compreender de que formas a comunicação comunitária se insere na política de comunicação organizacional corporativa. O estudo consiste em conhecer as experiências de comunicação comunitária desenvolvidas em três comunidades localizadas na zona rural de São Luís, Maranhão. São elas: Inhaúma, Coqueiro e Maruaí. Elas sofrem impactos das duas maiores empresas da indústria maranhense; o Consórcio de Alumínio do Maranhão (Alumar) e a Mineradora Vale, que tanto tem investimentos em programas sociais e de 
geração de empregos (diretos e indiretos) nessas localidades, bem como nutre as mesmas de impactos ambientais e sociais.

Apresentamos a seguir os caminhos percorridos para a construção de um Protocolo de Comunicação Comunitária voltado aos territórios, às comunidades e aos modos de vida no Maranhão; um método de correlação entre a teoria e a prática a partir das particularidades desse território, para assim, tornar-se uma possibilidade do mercado adotar e reaplicar.

As comunidades escolhidas para a realização desta pesquisa estão localizadas na zona rural de São Luís, vizinha da Alumar, bem como como das Área de Resíduo de Bauxita (ARB's) - os oito grandes lagos especialmente construídos para a disposição dos resíduos alcalinos proveniente do refinamento da bauxita e obtenção de Alumina. As comunidades são ainda cortadas pela Estrada de Ferro Carajás - da mineradora Vale, por onde o trem de minério e o trem de passageiros da empresa passam diariamente. As comunidades têm características de organização da sociedade civil, por meio de suas Associações Comunitárias de Moradores, que historicamente mantém o diálogo e construíram relacionamentos com ambas as empresas.

Nesse artigo apresenta-se Inhaúma, um exemplo de comunidade rural, como tantas outras localizadas em municípios maranhenses, afetadas diretamente e impactadas pela atuação dos empreendimentos e, por isso, recebem atenção e investimentos na tentativa de minimizar e mitigar possíveis danos causados. Uma política de gestão das empresas, mas também uma exigência das condicionantes ambientais dos órgãos governamentais, a fim de permitir a autorização, legalização e controle das atividades. E é a partir dessa orientação legal que elas se dedicam a pensar alternativas de como e onde o investimento financeiro será aplicado, objetivando harmonizar interesses das empresas, necessidades das comunidades e dar as respostas que atendam à legislação ambiental.

Assim, por meio dos seus Institutos, ambas as empresas destinam investimento social privado para ser aplicado em projetos e programas sociais desenvolvidos no território do Maranhão. Não é intenção desta pesquisa fazer julgamento, avaliação dos programas, ou análise dos resultados, nem tampouco mensurar a reputação dessas empresas. Apesar de já ter-se uma constatação social: no Maranhão, de um lado encontramos comunidades extremamente pobres e de outro há empresas que investem recursos em projetos sociais (culturais, ambientais, econômicos e humanitários).

\section{Comunicação Comunitária nas organizações}


A Comunicação Comunitária nas organizações privadas tornou-se uma ação estratégica e política, mas também um grande desafio, pois o profissional que assume essa área deve estar sempre cauteloso em atender: de um lado, o interesse da sua empresa, e de outro, respeitar, ouvir e atender às comunidades. E esse público hoje compreende seu lugar na sociedade como sujeitos que tem seus direitos assegurados e, muitas vezes, a garantia dos mesmos negada, seja pela ausência de políticas públicas básicas ou até mesmo pela negação do exercício da cidadania.

Se é evidente a mudança na esfera relacional entre os sujeitos e sua forma de viver no mundo, falar de ressignificação da comunicação comunitária na prática da comunicação organizacional integrada é entender e aceitar que vivemos em uma sociedade que tem hoje novas relações e precisam ser repensadas, seja do ponto de vista das pessoas, seja do ponto de vista das organizações. Estudar antigas e novas bases conceituais, e seus enlaces, se torna necessário para entender as práticas e o novo significado dado aos setores coorporativos e de diálogo com a comunidade, a partir da mudança na percepção do mundo, das organizações para seus públicos, assim como da própria sociedade com às organizações.

Deste modo, pensar em desenvolvimento, mundo do trabalho, inovação, direitos humanos conquistados, participação, produção cultural e exercício da cidadania planetária são entendimentos que devem fazer parte do repertório dos profissionais do campo da Comunicação.

Tendo em vista esse novo contexto, não dá para mensurar o grau de importância do que o mercado denomina de stakeholders ${ }^{1}$; o que é urgente é que se identifique quem são estes grupos, e seja qual for o diagnóstico realizado, a comunicação deve ser priorizada. Em suma, o resultado dessa pesquisa pretende ser um instrumento que colabore e fortaleça o exercício da Comunicação Comunitária com o recorte regional maranhense, Estado que ocupa os piores índices de desigualdade social do país, segundo os institutos de pesquisa, seja no âmbito da pobreza extrema ou na restrição ao acesso aos direitos básicos, mas que ao mesmo tempo possui um cenário natural singular além de uma cultura popular reconhecida internacionalmente e um povo forte, lutador e sobrevivente, em meio a tanta desigualdade social.

Kunsch (2016) ressalta que as organizações vivem em um sistema de relações, que influenciam e são influenciadas, tanto pelos meios econômicos, bem como o político

\footnotetext{
${ }^{1}$ Para Almeida e Bertucci (2010, p. 204) "numa perspectiva mais abrangente, stakeholders são todos aqueles que afetam e são afetados pelas ações organizacionais; numa perspectiva mais restrita stakeholders são aqueles grupos que contribuem de forma decisiva para a sobrevivência e o desempenho da organização".
} 
e o sociocultural. Fala ainda que não há como não acarear a realidade e as demandas sociais; que para fazer uma comunicação assertiva é necessário ter um entendimento integral sobre os fenômenos que vivem a sociedade, as "novas abordagens diante de violências, guerras, terrorismo, crises financeiras mundiais, desigualdades sociais, direitos humanos, alfabetização digital, multiculturalismo, novas competências etc." (KUNSCH, 2016, p. 39).

Vale ressaltar que todas as contribuições para a área da comunicação organizacional defendidas hoje por Margarida Kunsch são frutos de uma longa trajetória de pesquisa e de história vivida e são reconhecidas por esta pesquisa. Bem como as pesquisas e obras da professora Cicilia Peruzzo (1982, 1998, 2014), um marco e referência para os estudos da Comunicação do Brasil e que transformou a maneira de fazer Comunicação Comunitária na América Latina. E são parâmetros seguidos nesta pesquisa.

\section{Comunicação Organizacional Integrada: da teoria às práticas efetivas com as comunidades}

Com um olhar dialético e necessário para uma inicial reflexão, Scroferneker (2008, p. 15) fala de certezas e incertezas imbuídos no profissional que trabalha a Comunicação Organizacional, de certa forma justificando as cobranças sobre quem atua nessa área, "como sujeitos complexos, únicos e múltiplos, as compreensões sobre o mesmo fenômeno, no caso a Comunicação Organizacional, estará relacionada com as nossas percepções de mundo, nossas trajetórias individuais e também coletivas". Afinal, a realidade é mutante, bem como as pessoas, os relacionamentos, suas escolhas e as suas certezas.

O novo cenário mundial exige das organizações, em todos os setores, uma mudança em sua forma de atuação, seja para lidar com dinâmica das novas tecnologias, seja para enfrentar um mercado versátil, que se tornou mundial, com o advento e avanço da internet e sobreviver nesse mercado tão dinâmico e volátil.

Em todos os diagnósticos e em planejamentos empresariais, nunca foi tão presente o entendimento político e global do mundo, bem como a interatividade e o reconhecimento das pessoas, nas gestões coorporativas. Assim, conceitos como desenvolvimento local, sustentabilidade, inovação, direitos humanos, cultura, participação popular e cidadania, são entendimentos que devem fazer parte do repertório dos profissionais deste campo.

A Comunicação Organizacional vem assumindo, ao longo da história, uma posição indispensável dentre as alternativas de trabalhar a sobrevivência da organização 
(seja ela pública, privada ou do terceiro setor), tanto do ponto de vista de alcançar sua missão e objetivos estratégicos, ou para se construir um bom relacionamento com as pessoas, ou como é intitulado no mercado - os stakeholdes.

Almeida e Bertucci (2010, p. 194) buscaram traçar um entendimento, por meio de catalogação de conceitos de vários autores e de estabelecimento de uma classificação, para apresentarem um modelo de relacionamento para ser trabalhado entre stakeholders e uma empresa. Dessa forma, apontam, de forma sistematizada, que são estes grupos os mais relevantes de serem considerados dentro das políticas de gestão estratégica dos stakeholders. "os empregados, o meio ambiente, as questões reativas à diversidade no e do ambiente de trabalho, os consumidores, a segurança dos produtos e relação com a comunidade". Sendo este último a categoria que este estudo tenta voltar o olhar e a atenção das políticas de comunicação das organizações.

O entendimento sobre a adoção (e necessidade) de implementação de uma política de comunicação organizacional, aliada aos modelos de gestão administrativo e do planejamento estratégico das empresas, hoje, não é tão polêmica como em outros momentos. Nesse novo contexto, não dá para mensurar o grau de importância dos stakeholders. O que é urgente é que se identifique quem são estes grupos, e seja qual for o diagnóstico realizado, a comunicação deve ser priorizada.

\section{Novas dimensões da Comunicação Organizacional Integrada}

Já faz algum tempo que Kunsch (1997) apresentou um novo paradigma para trabalhar a comunicação nas organizações; o que ela batizou de "Comunicação Organizacional Integrada"; uma proposta de junção (mesmo reconhecendo as especificidades e diferenças de cada setor) das diversas subáreas da comunicação atuando de forma sinérgica, dividindo dessa forma: a comunicação administrativa, interna, institucional e mercadológica. A autora propõe que estas áreas da comunicação organizacional sejam exercidas de maneira integrada, tendo como alicerce a missão, valores e objetivos gerais das organizações, bem como respeitando e buscado cumprir os planejamentos, as metas e as especificidades de cada um desses seguimentos.

Mais recentemente, Kunsch (2016) sugeriu quatro novas dimensões a serem trabalhadas na Comunicação Organizacional integrada: instrumental, humana, cultural e estratégica. Conforme a autora, a dimensão instrumental, a que se direciona às tarefas técnicas e cotidianas, baseadas no método funcional, é a que ainda é predominante nas organizações. Segundo a autora, esse método ainda ver a comunicação de forma linear e não de forma sistêmica, onde contextos e influência externa, bem como questões 
subjetivas dos públicos deveriam ser considerados, buscando apenas se cumprir ações para se constar em números e resultado nos balanços de uma organização.

Já a dimensão humana, aquela que deveria ser pensada como primordial, pela própria natureza, e não é. A professora traz inúmeras ponderações das razões da relevância de ser uma prioridade pensar nas pessoas. Segundo ela, a partir do momento que a comunicação começa a fazer parte do planejamento estratégico das organizações, o fator humano, relacional, de produção de sentidos e a visão do contexto histórico deverá ser priorizado, caso se queira que a comunicação seja efetiva, eficaz e atenda o que realmente for a sua intenção dentro de cada organização. Muito além de um despreparo dos gestores de comunicação, essa dimensão não é trabalhada por reflexo das relações de dominação e hegemonia, de poder e subalternização, herança do sistema capitalista. E acredita-se, que conhecer a cultura do local, mais do que os subsídios para produção das ferramentas instrumentais, deva ser adotada como uma prática e política estratégica.

E a última dimensão, a estratégica, deve ser repensada, conforme Kunsch (2016), a cada local, realidade e experiência. Ela pontua que é preciso se pensar em "uma nova estratégia" de gestão, para verdadeiramente se efetivar uma nova dimensão estratégica de comunicação. E é sobre essa nova estratégia das organizações que se objetiva trabalhar e colaborar na pesquisa em curso.

As mudanças das relações não aconteceram de um dia para outro, o engajamento de stakeholders nos planejamentos das ações das empresas foi reflexo de uma conquista de direitos, onde nessa nova conjuntura a "sociedade civil parece assumir seu papel histórico de não apenas esperar que o Estado a atenda em suas necessidades, mas de fazer a sua parte na luta para democratizar a cidadania", como afirma Peruzzo (apud KUNSCH, 2007, p. 57). A comunidade assume uma nova postura cidadã e de protagonista buscando atuar como sujeito, ainda mais nos processos de comunicação, participação e mobilização.

\section{A Comunicação Comunitária no contexto da Comunicação Organizacional: o diálogo com as comunidades}

Falar de uma dimensão estratégica na Comunicação Organizacional é rever diversas práticas das suas áreas. Uma delas é a Comunicação Comunitária. O que se torna um grande desafio, pois o profissional que assume essa área deverá estar sempre cauteloso em atender: de um lado o interesse da sua empresa, e de outro respeitar, ouvir 
e atender aos interesses das comunidades, que reivindica em participar dos processos de desenvolvimento.

Diante as tendências de restruturação da Comunicação Organizacional delineado por Margarida Kunsch (2016), com inspiração no modelo de participação e comunicação, proposto por Peruzzo (2014), bem como na experiência adquirida, a partir da realidade de comunidades e ações de programas sociais desenvolvidos pela autora deste trabalho no estado do Maranhão, apresenta-se aqui um modelo conceitual de gestão da comunicação comunitária organizacional, como uma proposta, com base em conceitos necessários para sua efetiva prática de ação, que será base para construção do Protocolo de comunicação comunitária proposto.

Pontua-se que o delineamento desse modelo ilustrado na figura 1 , registra uma possível representação de elementos teóricos e conceituais necessários para se iniciar qualquer trabalho com comunicação comunitária.

Figura 1 - Mapa conceitual de gestão da comunicação comunitária organizacional

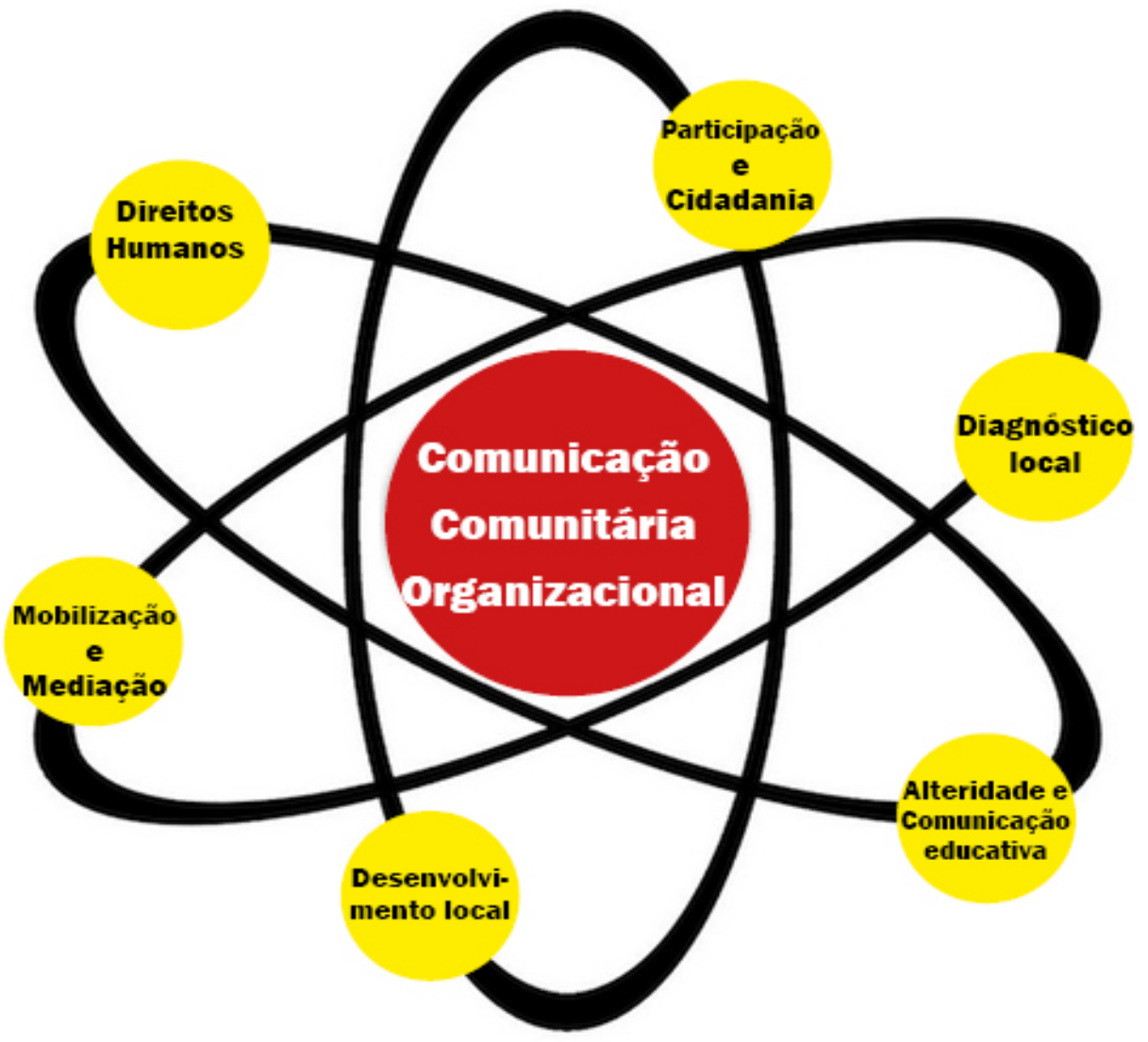

Fonte: As autoras (2020). 
Cada um desses elementos, que ainda serão validadas durante a pesquisa empírica, foram baseadas em experiência prática vivida nas relações entre empresas e comunidades no Maranhão e estão descritas a seguir:

- Direitos humanos: De acordo com o artigo 19 da Declaração dos Direito Humanos, das Nações Unidas, de 1948: "todo indivíduo tem direito à liberdade de opinião e de expressão; este direito inclui a liberdade de, sem interferência, ter opiniões e de procurar, receber e transmitir informações e ideias por quaisquer meios, independentemente de fronteiras" (ONU, 1948). Acredita-se ser impossível pensar em uma sociedade democrática sem uma comunicação democrática, e assim perpassa a pertinência em se defender a comunicação como um direito humano. "Uma das múltiplas instâncias pelos quais o homem pode exercer esse direito e esse dever é a comunicação social" (PERUZZO, 1998, p. 275), um exemplo prático da aplicação desse conceito praticado pelas s empresas Alumar e Vale no estado do Maranhão é que em ambas existe um setor de relacionamento com a comunidade, ligados às equipes de comunicação, que buscam promover um espaço de diálogo e construir ferramentas de acesso à informação.

- Diagnóstico local: entende-se que para desenvolver qualquer programa voltado às demandas comunitárias, é imprescindível conhecer a realidade local, identificando as em que é possível se somar para colaborar com o desenvolvimento humano, social, econômico, político e ambiental, mapeando todos os programas e projetos que são desenvolvidos, tanto pela iniciativa governamental ou de organizações não-governamentais ou dos movimentos sociais, que normalmente tem um acúmulo significativo e nem sempre sistematizado sobre os territórios. A mineradora Vale, por exemplo, elabora um Relatório de Sustentabilidade, que tem seu conteúdo voltado às orientações e aos seus compromissos relacionados ao Pacto Global das Nações Unidas, ao Conselho Internacional de Mineração e Metais e aos Objetivos do Desenvolvimento Sustentável (ODS). A intenção dessa política, segundo a empresa, é ter um diagnóstico permanente, que apresente possibilidades concretas para promover o desenvolvimento sustentável.

- Participação e cidadania: A realização plena da cidadania é a participação, por meio da liberdade, criação de espaço de democráticos, onde seja 
possível o estabelecimento da igualdade e do bom relacionamento, bem como o respeito às realidades locais. São as reflexões que nos traz Peruzzo (2014, p. 46), pela própria natureza, pelos instrumentos que possibilitam a relação e troca de informações e saberes, a comunicação desempenha papel central na construção da cidadania. Diz ainda que existem três modalidades de participação popular: a participação passiva, a participação controlada e a participação-poder, "que não são necessariamente cronológicas nem se excluem mutualmente, porque podem concretizar-se dialeticamente" (PERUZZO, 1998, p. 78), Algo que se pretende investigar nesta pesquisa é esse nível de participação, especialmente no Maranhão onde a pobreza, falta a escolaridade e a negação de direitos é uma realidade. Um exemplo desta tentativa de envolvimento e participação acontece na Alumar, onde no Plano Básico Ambiental apresentado para a Secretaria de Meio Ambiente do Estado do Maranhão (SEMA), referente à autorização da licença da construção de uma Área de Resíduos de Bauxita (ARB), se prontifica "a comunicar" as comunidades vizinhas, como os moradores de Inhaúma (São Luís), a respeito do início das obras, o planejamento e os impactos com a implantação da obra, sejam impactos ambientais ou sociais, bem como vagas de emprego destinadas às comunidades;

- Mobilização e mediação: trata-se de um processo legítimo e essencialmente político, uma prática historicamente constituída, dotando os indivíduos de liberdade e autonomia na configuração de suas redes de relações. O recorte específico da mediação aqui é a tentativa de entender a como se correlacionam a identidade, os saberes e a história, além dos processos comunicacionais, levando em consideração que "não podemos estudar processos históricos desconectados do mundo social no qual estamos inseridos. Não podemos estudar processos comunicacionais sem a necessária correlação com o tempo social de sua produção e o espaço social de sua relação" (BARBOSA; RIBEIRO, 2011, p. 25). A comunicação adequada à mobilização social é aquela que assume uma característica dialógica, libertadora e educativa. Entendendo ainda mobilização como uma convocação de vontades, na qual as pessoas são chamadas a agir de forma responsável pelo bem de todos, "a mobilização social é uma reunião de sujeitos que definem objetivos e compartilham sentimentos, 
conhecimentos e responsabilidades para a transformação de uma dada realidade, movidos por um acordo em relação a determinada causa de interesse público" (HENRIQUE et al., 2007, p. 36).

- Desenvolvimento local: A prática de desenvolvimento de programas sociais se tornou uma política de gestão das grandes empresas no mundo inteiro, seja visando a construção do bom relacionamento comunitário ou em atendimento às exigências da Legislação Ambiental Brasileira, ou ainda, atender aos interesses de seus públicos, que hoje compreende seu lugar na sociedade, como sujeito. Dessa forma, Peruzzo (apud KUNSCH, 2007, p. 51) defende que "um modelo de comunicação que pressupõe um desenvolvimento sustentável e participativo é o único aceitável na atual conjuntura brasileira". A intenção de continuidade desta pesquisa é perceber de que formas essas empresas assumem essa responsabilidade com a vida humana e o planeta.

- Alteridade e comunicação educativa: "Na comunicação, eu acolho a alteridade do Outro, abro espaço para ela, vivencio o que ela pode produzir e mim. Eu não a aprisiono nem a repugno" (MARCONDES FILHO, 2018, p. 80). Entender e viver alteridade deverá ser a escolha do profissional que busque trabalhar a comunicação comunitária. Fala-se aqui de escolha, pois se crê que não é técnica, não existe um manual de normas e procedimentos para se ter alteridade ou empatia. Porém, se defende que o profissional que optar em trabalhar a comunicação comunitária deverá ter, por princípio, o respeito ao Outro, o reconhecimento das diversidades e atender aos valores e os direitos de uma sociedade. Para que assim consigam fazer com que os processos educomunicativos promovam espaços dialógicos e que se constituam verdadeiramente horizontais. Na Alumar, essa responsabilidade é da equipe de Relações Institucionais; e na Vale, da equipe de Relacionamento com a Comunidade; ambas formadas por uma equipe multidisciplinar, com planejamento adequado aos diagnósticos, recursos destinados e ações de comunicação definidas. Nossa investigação busca compreender como se faz a comunicação comunitária a partir de duas experiências distintas, com sujeitos e interesses distintos, mas a partir de particularidades da cultura e da identidade no território do Estado do Maranhão. 
"A comunicação popular contribui para a democratização da sociedade e a conquista da cidadania" (PERUZZO, 1998, p. 158). Comungando com o discurso da autora, que se crê ir ao encontro com todos que reconhecem a comunicação como um direito humano, pretende-se, para além da definição conceitual, visualizar os enlaces entre esses conceitos e as práticas sociais, bem como a aplicabilidade na realidade e particularidade do Maranhão.

\section{A história e os sujeitos das comunidades da Zona Rural de São Luís (MA)}

Este trabalho investiga três comunidades impactadas tanto pela empresa Vale como pela Alumar, que ficam localizadas na Zona Rural de São Luís (MA): Maruaí; Inhaúma; e Coqueiro - localizadas na BR 135. Neste artigo, apresenta-se dados da comunidade de Inhaúma, localizada na BR 135, ao lado da Alumar e dividida pela Estrada de Ferro Carajás, Inhaúma, segundo a moradora Gilma Marques² (informação verbal):

Eu vou fazer 35 anos e moro aqui, desde criança. Eu nasci na Estiva. E assim que eu nasci lá eu vim morar aqui em Inhaúma. Meu pai, antes de morrer, falava que Inhaúma era centenária, e pelo que eu entendi, aqui começou com uma estradinha de terra, aí o povo foi chegando, tirando o terreno e construindo suas casas. Eu não sei exatamente como foi fundada Inhaúma, mas sei que ela é centenária.

De acordo com as informações colhidas, a comunidade tem 307 casas. As principais fontes de renda são, nessa ordem: $1^{\circ}$ ) de moradores que trabalham na construção, no supermercado Mateus ${ }^{3}$ e nas empresas; $2^{\circ}$ ) de moradores que vivem do benefício do Bolsa Família; $3^{\circ}$ ) e que sobrevivem de aposentadoria. Mas, há um grande número de desempregados, especialmente os jovens.

Para conhecer a organização da comunidade nos grupos de participação popular, realizou-se uma dinâmica em grupo, onde foram distribuídas cartelas com nomes de instituições comunitárias e eles deveria apontar as que existiam em Inhaúma e organizálas de forma hierárquica, quem tinha influência política e de articulação no lugar.

Apesar de todas essas organizações, Dona Glória, principal liderança da comunidade hoje, diz que é com a Associação de Moradores que as empresas mantem relacionamento e é a porta de entrada na comunidade. Sobre a história da Associação Dona Glória (informação verbal) ${ }^{4}$ nos revela:

\footnotetext{
2 Entrevista concedida por Gilma Marques à pesquisadora Amarilis Cardoso Santos em janeiro de 2021 em São Luís-MA (MARQUES et al., 2021).

3 Principal rede de supermercados da região.

${ }^{4}$ Entrevista concedida por Maria da Glória Ferreira à pesquisadora Amarilis Cardoso Santos em janeiro de 2021 em São Luís-MA (MARQUES et al., 2021).
} 


\begin{abstract}
Associação existe há 35 anos, mas foi fundada há 34 , no dia 25 de março de 1987. O que sei da história da associação é que moradores mais antigos (como o seu Agenor, seu Libanio, Brasiliano, José Moreira e a família de Maria Sena). Não tinha estrada e foi quando eles se organizaram para pedir a um vereador para abrir a rua. A rua principal, que dá acesso à Associação, para ser criada foi muita luta, quase se morre e se mata por isso. Naquele tempo, a Associação foi muito envolvida para situações de festas. Depois da minha gestão, que virou o olhar para os projetos sociais. Minha gestão começou em 17 de abril de 2016. Porque era festa? Porque tinha uma tradição do mês de junho ter o festejo de Santa Luzia e era a Associação e a Igreja católica que organizavam, porque elas eram formadas pelas mesmas pessoas. Acabou sendo esse o principal objetivo da associação do bairro: dela ser atribuída ao lugar de festas. Foi também com a luta deles que a Associação começou a desenvolver o bairro, foi com ela que veio a escola, que vieram os postes. Essa foi a história da associação.
\end{abstract}

Assim como em outras comunidades da Zona Rural de São Luís, em Inhaúma falta muita assistência e acesso a políticas públicas. Somente em 2020 foi asfaltada, não tem posto de saúde, nem Centro de Assistência Social (CRAS), há pessoas em condições de pobreza, desemprego e o medo da violência (presença de facções) é algo recorrente nas falas dos entrevistados. Hoje, é considerada público, mantém relacionamento e diálogo com as empresas Alumar e Vale, bem como recebem projetos e benefícios provenientes de reparação social e ambiental ou ações de voluntariado.

Em conversa inicial com a jornalista Déborah Maria Martins Ferreira, gerente de relações com comunidades da Vale, no Maranhão, a cada ano são priorizadas ações, projetos sociais e as comunidades que receberão investimentos (informação verbal) ${ }^{5}$, ela informou que nas três comunidades objeto deste estudo não houve investimento social, "nos últimos anos eles vieram sendo contemplados com projetos de geração de renda e em projetos mais estruturantes, em 2020 foi feita a atuação junto as UBS's dessa região, no combate ao COVID, doamos celulares para teleatendimento e EPIs", dentre as Unidades Básicas de Saúde (UBS's) contempladas estavam as comunidades de Coqueiro e Pedrinhas, que atendem as pessoas daquela região.

Este trabalho tem o intuito de conhecer melhor os projetos estruturantes e de geração de renda que foram financiados pela Vale nas três comunidades estudadas, bem como o legado que ficou para as comunidades. "Importante apontar sempre o desafio que é realizar ações com a comunidade dentro de um padrão mínimo de compliance" (informação verbal) (FERREIRA, 2021), ressaltou a gerente ao encerrar este primeiro contato. Evidencia-se aqui uma dificuldade, em meio ao contexto social, econômico e

\footnotetext{
${ }^{5}$ Entrevista concedida por Débora Maria Ferreira à pesquisadora Amarilis Cardoso Santos em janeiro de 2021 em São Luís-MA. Entrevista por telefone (FERREIRA, 2021).
} 
cultural, de se desenvolver um trabalho com as comunidades no Maranhão, algo que será aprofundado com as empresa posteriormente durante o trabalho de campo desta pesquisa em andamento.

\section{O caso da Associação de Moradores de Inhaúma}

Parece ser algo simples acreditar que hoje no contexto de uma sociedade com direitos garantidos, com uma legislação específica voltada à fiscalização dos impactos sociais e ambientais, as empresas e organizações teriam mais atenção ao assumir e reparar os problemas causados por seus impactos, de modo particular aqueles que relacionados ao ser humano, às comunidades vizinhas.

Mas, não é simples! Não é prática de todas das organizações, apesar de que muito já se avançou. Especialmente por temos uma sociedade mais consciente e participativa, que ao longo do tempo foi colaborando também para a formatação de um novo modelo de economia e de organização.

As grandes mudanças de paradigma econômico na história da humanidade trazem consigo não só revoluções nas comunicações e nos regimes de energia como em configurações novas e poderosas que transformam a vida econômica da sociedade. Cada nova matriz comunicação/energia/transporte também transforma a consciência humana estendendo o impulso empático ao longo de domínios temporais e espaciais mais amplos, reunindo os seres humanos em famílias simbólicas maiores e sociedades mais interdependentes (RIFKIN, 2016, p.344).

O autor registra uma reflexão oportuna a respeito da sociedade na atualidade. Nunca se falou tanto de empatia, se dispor a estar no lugar do outro, como hoje. O autor fala da evolução da consciência humana chegando a afirmar que "criar empatia é civilizar [...] civilizar é criar empatia" (RIFKIN, 2016, p.347), onde esse exercício prático em sentir a alegria, a tristeza, o medo, a esperança, as dores, a negação de direito e sofrimento do outro, não é só um ato de solidariedade com o outro, mas um reconhecimento de si mesmo e da existência e essência do outro. O que no entendimento de Lévinas (1980) esse acolhimento do outro está para além da empatia, pois nem sempre é possível sentir o que sente o outro, mas sempre é possível reconhecer este outro, suas questões particulares subjetivas, assim como também aquilo que liga esse eu e este outro, e a esta compreensão mais ampliada ele define como alteridade:

A maneira do Eu contra o "outro" do mundo consiste em permanecer, em identificar-se existindo aí em sua casa. [...] Encontra no mundo um lugar e uma casa. Habitar é a própria maneira de se manter [...]. O "em casa" não é um continente, mas um lugar onde eu posso, onde, 
dependente de uma realidade outra, sou, apesar dessa dependência, ou graças a ela, livre. [...] Tudo está ao alcance, tudo me pertence; tudo é de antemão apanhado com a tomada original do lugar, tudo está compreendido. A possibilidade de possuir, isto é, de suspender a própria alteridade daquilo que só é outro à primeira vista e outro em relação a mim - é a maneira do Mesmo. (LÉVINAS, 1980, p. 25).

O autor nos remete a refletir que o exercício da alteridade é também se dispor a percepção do mundo e do outro, possibilita, sobretudo, a oportunidade de (re) conhecer a si mesmo, afinal "a alteridade só é possível a partir de mim" (LÉVINAS, 1980, p. 26).

Transformaram-se modelos de gestão e de negócio ao longo da história, mas as pessoas também mudaram. Em todas as análises de conjuntura, diagnósticos e planejamentos estratégicos, nunca foi tão presente o reconhecimento das pessoas, membro de uma comunidade, nas gestões coorporativas, como acontece com o relacionamento estabelecido entre a comunidade de Inhaúma e as empresas Vale e Alumar, que segundo Dona Glória (informação verbal), os projetos não iam para comunidade porque não se corria atrás:

De 2016 para cá a gente, quando eu cheguei conseguiu fazer, com muito amor e com muito carinho essa mudança. Foi um embate muito forte, a coca-cola, por exemplo, ela não abria as portas, mas hoje ela tá aí com o diálogo com as comunidades. Hoje a gente tem um convívio muito bom com as empresas Vale e Alumar, mas tudo dependia também do amor e também de diálogo, eu acho que era isso que precisava. Porque da minha gestão, de 2016 para cá, tudo mudou com as comunidades, o relacionamento mudou! Tem uma liderança que diz que foi por mim pela minha chegada, mas não foi! Eu digo que foi por uma ação coletiva!

O exercício da cidadania, as conquistas de direitos e as possibilidades de participação, por meio dos espaços conquistados, fez desse público também estratégico para as organizações. Por exemplo, como acontece hoje com a Alumar e as comunidades vizinhas segundo Maria da Glória Ferreira e Gilma Marques (informações verbais) ${ }^{7}$ :

Na Alumar o problema, era só a questão das vagas de emprego. Mas, hoje, depois de negociação e diálogo, isso foi amenizado. Porque hoje Alumar, por meio da FIDENS ela destina vagas de emprego para as obras de instalação e de construção para todas as 14 comunidades adjacentes à Alumar e da FIDENS.

\footnotetext{
${ }^{6}$ Entrevista concedida por Maria da Glória Ferreira à pesquisadora Amarilis Cardoso Santos em janeiro de 2021 em São Luís-MA (MARQUES et al., 2021).

7 Entrevista concedida por Maria da Glória Ferreira e Gilma Marques à pesquisadora Amarilis Cardoso Santos em janeiro de 2021 em São Luís-MA (MARQUES et al., 2021).
} 
É por isso, que se defende aqui que em cada localidade a comunidade poderá ser percebida a partir do entendimento de como se contemplam as alteridades do eu e do outo, reconhecendo os aspectos particulares do modo de vida maranhense, características culturais, de identidade, de identificação, a peculiaridade local, suas histórias, experiências e subjetividades. Que as empresas percebam para além das reparações dos seus impactos sociais e ambientais, mas reconheçam o seu lugar dentro daquela comunidade, como parte dela também.

Inhaúma (desde a construção da Estrada de Ferro Carajás) é cortada, dividida pela linha do trem. Apesar de reconhecer o bom relacionamento existente com as empresas, na comunidade existe esse impacto para vida toda daquele lugar, pois a empresa vive com eles naquele lugar. Como bem pontua Sodré (2014, p. 203): "o conceito de comunidade (e não qualquer entidade 'comunitarista') quem nos diz que ser é estarjunto, é ser-com. Ou seja, não se parte da ideia de um 'eu' ou de um 'não eu', mas de um 'com' constitutivo".

O autor reforça que essa relação se dá por uma dialética condição ou não de reciprocidade, uma hora entrega total em outra o afastamento. E essas contradições também merecem observação quando se tentar construir o conceito de comunidade (engessado) nesse novo modelo de sociedade que se vive, como acontece na realidade da Comunidade de Inhaúma.

Fala-se aqui de uma escolha, pois se crê que não é técnica, não existe um manual de normas e procedimentos para se construir alteridade ou sentimento de comunidade, mas, é um processo de consciência e sensibilização

A finalidade do Protocolo de Comunicação Comunitária, aqui proposto, é se tornar uma referência prática para a constituição de programas de comunicação comunitária, integrados aos programas de comunicação organizacionais, sistematizado e apresentando ferramentas acessíveis e (re)aplicáveis para a prática nas Organizações (de qualquer natureza) a partir da percepção e do olhar sobre a existência do outro, e sobretudo do respeito à vida destes.

\section{Trajetória metodológica}

Este trabalho é fundamentado a partir dos estudos da pesquisa qualitativa de Deslauriers e Kérisit (2008, p. 132), diz que "para além dos argumentos de ordem metodológica, parece que a pesquisa qualitativa se aplica melhor a certos tipos de pesquisa", e apresentando os argumentos, descridos abaixo, orienta a aplicabilidade da pesquisa qualitativa: a) pesquisas descritivas e exploratórias: que possibilitam a 
aproximação com o fenômeno estudado e por ser descritiva (em um Protocolo) servirá aqui para conhecer a realidade local, e as experiências de comunicação comunitária desenvolvidas pelas duas maiores empresas da indústria do Maranhão (Vale e Alumar), bem como os entraves existentes entre as pessoas das comunidades e as empresas. Para isso será usado como corpus documental os relatórios de Sustentabilidade e Balanço Social, que são documentos públicos das empresas Vale e Alumar, dos anos de 2018, 2019 e 2020. b) Estudo do cotidiano e do ordinário: "O Objetivo de uma pesquisa qualitativa pode ser o de dar conta das preocupações dos atores sociais, tais quais elas são vividas no cotidiano" (DESLAURIERS; KÉRISIT, 2008, p. 130). Para delimita-se como sujeito da pesquisa três comunidades, mais especificamente as Associações Comunitárias de Moradores de três comunidades - bairros da zona rural de São Luís (MA), localizado na BR 135 (acesso à capital): Maruaí, Inhaúma e Coqueiro. A escolha da amostragem se deu por estas possuírem características particulares; pela situação de violência (domínio de facções, violência e criminalidade) presentes nas outras comunidades; e por terem uma Associação Comunitária que se dispôs ao diálogo e intervenção com a comunidade. "Geralmente, para a coleta das informações, a pesquisa qualitativa recorre à observação participante e à entrevista" (DESLAURIERS; KÉRISIT, 2008, p. 140). E a entrevista foi à ferramenta escolhida por esta pesquisa.

Como a pesquisa que enaltece a vida dos atores sociais, não os restringindo a um mero objeto descritivo, "um dos objetos privilegiados da pesquisa qualitativa é, portanto, o sentido que adquirem a ação da sociedade na vida e os comportamentos dos indivíduos, assim como o sentido da ação individual quando ela se traduz em ação coletiva" (DESLAURIERS; KÉRISIT, 2008, p. 131).

A intenção é se realizar a pesquisa empírica em dois momentos: o primeiro é o trabalho de campo focado no conhecimento dos sujeitos e posteriormente da validação da metodologia e ferramentas construídas ao longo desta pesquisa, para assim consolidar o Protocolo de Comunicação Comunitária.

Após as experiências de campo, dados sistematizados e validação, pretende-se apresentar esta metodologia de forma criativa, ilustrada e acessível, utilizando um projeto de design desenvolvido especialmente para este produto final, a fim de que seja possível apresentar o Protocolo proposto para este trabalho com alta fidelidade, interfaces e interação do produto com o usuário.

\section{Proposições para a criação do Protocolo}


Tendo como base o paradigma epistemológico desenvolvido Herbert Simom (1996), será utilizada para construção do produto dessa pesquisa o design science (DS), que Santos (2018) atesta como um caminho possível para a pesquisa aplicada à comunicação, voltada a desenvolver soluções para responder a problemas. "Caracterizase pelo desenvolvimento de pesquisas orientadas para o enfrentamento de problemas reais e a proposição e/ou prescrição de soluções, denominadas de artefatos, que representam melhorias em relação ao que já existe, ou ainda, respostas totalmente inéditas" (SANTOS, 2018, p. 22).

Para essa produção tomar corpo em um documento, serão levadas em consideração reflexões, apontamentos e aprendizados levantados com as teorias e obras dos autores pesquisados e estudados; a experiência vivida junto às comunidades maranhenses, amostra deste trabalho. Entre as categorias e classificações dos artefatos apontadas pelo design science (DS), esta pesquisa adotará métodos na perspectiva de Santos (2018, p. 26), revisitando March e Smith (1995), definiu como: "conjuntos de procedimentos e ações orientados para o desempenho de determinada tarefa ou solução de um dado problema. Os métodos podem estar relacionados a modelos previamente estabelecidos, sendo um passo a mais na escala entre abstração e tangibilidade da solução".

Neste sentido, propõem-se que o Protocolo tenha 6 eixos norteadores:

1- Apresentação: Contar a história! A história do mestrado, da natureza desta pesquisa, seus objetivos, e, por fim a trajetória e motivação em se construir este Protocolo, bem como a importância de ver a comunicação como um direito humano e de olhar para esse direito, do ponto de vista do local.

2- Base conceitual: A apresentação do "Mapa conceitual de gestão da comunicação comunitária organizacional", inspirado, sobretudo nas Teorias da Comunicação Comunitária e de Participação de Cicilia Peruzzo (2014) com apresentação dos conceitos: direitos humanos; participação e cidadania; diagnóstico local; mobilização e mediação; desenvolvimento local; e alteridade e comunicação educativa.

3- Diagnóstico local: A apresentação do "Mapa da Alteridade para Comunicação Comunitária", conexões conceituais com a alteridade, que teve como referências a Teoria da Recepção e da Mediação, de Jesús Martín-Barbeiro (1997), que será construído a partir do estudo dos 
fenômenos das mediações: a cotidianidade familiar, a temporalidade social e a competência cultural.

4- Articulação Social: Modelo que ainda será pensado junto às comunidades e entrevistas realizadas com os profissionais que desenvolvem o trabalho de comunicação comunitária na Vale e na Alumar. Onde se pretende apresentar: estratégias de mobilização, convocação, sensibilização, deliberação e articulação de atores sociais.

5- Programa de Comunicação Comunitária: um modelo de gestão e organização de um projeto, que vá ao encontro à peculiaridades do Maranhão, isto é, que dialogue com as seguintes áreas: desenvolvimento local, direitos humanos, cultura e comunicação.

6- Avaliação e reaplicação: apresentar um modelo que diga aos sujeitos envolvidos que sempre é possível fazer melhor, que a participação social e o protagonismo é uma oportunidade para de se sair da condição de indivíduo para ser sujeito e cidadão nos processos de construção social.

Fazer sentido, propiciar uma solução e contribuir com a área de Comunicação Comunitária são as propostas deste estudo que visa deixar uma contribuição ligada à ação da prática profissional a partir da contemplação da regionalidade. Para isso, será necessária uma abordagem de natureza interdisciplinar, buscando solucionar problemas e construir um protocolo experimental de ação. Assim, após essa pesquisa experimental, o estudo se voltará à realização e orientações da pesquisa aplicada "utilizado para caracterizar iniciativas de cunho científico orientadas à solução de problemas reais ou de ordem prática" (SANTOS, 2018, p. 20); um estudo aplicado à coleta de dados voltados à solução válida e eficaz para o enfrentamento de um problema real.

\section{Considerações Finais}

"A tradição da pesquisa qualitativa frequentemente insistiu no caráter pessoal dos trabalhos. O envolvimento do pesquisador em seu objeto e, portanto, emocional e constituiria o ponto de partida" (DESLAURIERS; KÉRISIT, 2008, p. 131). Como exprimiram os autores, esta pesquisa é fruto de uma escolha afetiva e das dificuldades encontradas, ao longo de anos, para fazer com que as organizações compreendessem a importância e como executar (na prática) o trabalho da comunicação comunitária, a partir da particularidade do território e das comunidades locais maranhenses. Esta questão problema que colocamos em discussão visando levantar as ponderações e sugestões, 
para que se possa sistematizar, e finalmente apresentar, com criatividade e inovação (na esfera local), uma possível solução ao nosso problema: um Protocolo de Comunicação Comunitária voltado a atuação aos territórios, às comunidades e ao modo de vida no Maranhão.

Apesar de não ser uma preocupação recente, as organizações mantêm práticas antigas, especialmente no que diz respeito às atividades de comunicação comunitária, com projetos pensados de forma descontextualizada da realidade local, sem leitura da conjuntura, identificação das identidades dos indivíduos ou, em muitos casos, experiências inovação e empatia.

Uma compreensão equivocada em se pensar que ações voltadas para o stakeholders comunidade não merecessem transcender e acompanhar o próprio desenvolvimento do mundo, das tecnologias e, sobretudo, das pessoas. É como se por causa das condições de submissão e de pobreza, as comunidades se contentassem com as velhas práticas da política do "pão e circo", descontextualizadas dos reais problemas sociais enfrentados na região.

Com a compreensão de que não está se propondo um método para os movimentos populares e muito menos se apropriando de sua história, prática política, de mobilização, de participação e de comunicação comunitária, para às organizações privadas, mas, sim buscando apresentar um modelo a se adequar às políticas de comunicação organizacional, entendendo e reconhecendo a trajetória da comunicação popular e comunitária e seu legado na construção da cidadania no Brasil.

Seguindo as orientações do documento de área de Comunicação e Informação da Coordenação de Aperfeiçoamento de Pessoal de Nível Superior (CAPES) sobre a formação dos profissionais na pós-graduação stricto sensu, nas modalidades de mestrado e doutorado profissionais, este trabalho busca um olhar interdisciplinar ao deixar uma solução e legado construtivo à sociedade e ao mercado de trabalho. Para isso, segue como norte de orientação da CAPES (2019, p. 16-17): "visando ao atendimento das demandas sociais, organizacionais ou profissionais e do mercado de trabalho; à produção e aplicação de conhecimentos para a sociedade; à adequação da formação profissional a diferentes tipos de entidades". Tudo isso, por meio de uma ferramenta de comunicação organizacional, que se crê, deseja e espera poder colaborar tanto com a academia, com o mercado e os com profissionais que atuam com comunicação comunitária no Estado do Maranhão.

\section{Referências}


ALMEIDA, Ana Luísa de Casto; BERTUCCl, Janete Lara de Oliveira. Gestão estratégica de stakeholders. aspectos relevantes na definição de política de relacionamento. In:

BARBOSA, Marialva Carlos; RIBEIRO, Ana Paula Goulart. Comunicação e história. Florianópolis: Isular, 2011.

CAPES. Documento de área: comunicação e informação. Brasília: MEC, 2019. Disponível em: $\quad$ https://www.capes.gov.br/images/Documento_de_\%C3\%A1rea_2019/ COMUNICACAO.pdf. Acesso em: 12 jan. 2020.

DESLAURIERS, Jean-Pierre; KÉRISIT, Michele. O delineamento da pesquisa qualitativa. In. POUPART, Jean et al. A pesquisa qualitativa: enfoques epistemológicos. Rio de Janeiro: Vozes, 2008.

FERREIRA, Déborah Maria Martins. Entrevista II [jan. 2021]. Entrevistadora: Amarilis Cardoso Santos. São Luís, 2021. Entrevista por telefone.

HENRIQUE, Márcio Simeone; BRAGA, Clara Soares; SILVA, Daniela Brandão do Couto e; MAFRA, Rennan Lanna Martins. Relações públicas em projeto de mobilização social: funções e características. In $n$. HENRIQUE, Márcio Simeone. Comunicação e estratégias de mobilização. Belo Horizonte: Autêntica, 2007.

KUNSCH, Margarida M. Krohling (org.). Relações públicas e modernidade: novos paradigmas na comunicação organizacional. São Paulo: Summus, 1997.

KUNSCH, Margarida M. Krohling. Comunicação organizacional estratégica: aportes conceituais e aplicados. São Paulo: Summus, 2016.

LÉVINAS, Emmanuel. Totalidade e infinito. Tradução de José Pinto Ribeiro. Lisboa: Edições 70, 1980.

MARCONDES FILHO, Ciro. Comunicação ou metodologia?: a fundação de um campo da comunicação. São Paulo: Paulus, 2018.

MARQUES, Gilma; FERREIRA, Maria da Glória; FERREIRA, Inaldo; SANTOS, Maria. Entrevista I [jan. 2021]. Entrevistadora: Amarilis Cardoso Santos. São Luís, 2021.1 arquivo mp3 (78 minutos).]

ORGANIZAÇÃO DAS NAÇÕES UNIDAS. Declaração Universal dos Direitos Humanos. 1948. Disponível em: https://www.unicef.org/brazil/declaracao-universal-dos-direitoshumanos. Acesso em: 12 dez. 2020.

PERUZZO, Cicilia Maria Krohling. Comunicação nos movimentos populares: a participação da construção da cidadania. São Paulo: Vozes, 1998.

PERUZZO, Cicilia Maria Krohling. Comunicação para o desenvolvimento, comunicação para a transformação social. In: MONTEIRO NETO, Aristides (org.). Sociedade, política e desenvolvimento. Brasília: Ipea, 2014.

PERUZZO, Cicilia Maria Krohling. Relações públicas no modo de produção capitalista. São Paulo: Summus, 1982.

RIFKIN, Jeremy. Sociedade com custo marginal zero: a internet das coisas, os bens comuns colaborativos e o eclipse do capitalismo. São Paulo: Makron Books, 2016.

SANTOS, Márcio Carneiro. Pesquisa aplicada em comunicação: o estranhamento da interdisciplinaridade que nos assombra. Comunicação \& Inovação, v.19, n. 41, v. 18-33, 2018.

SCROFERNEKER, Cleusa Maria Andrade. O diálogo possível: comunicação organizacional e paradigma da complexidade. Porto Alegre: EDIPUCRS, 2008.

SODRÉ, Muniz. A ciência do comum: notas para o método comunicacional. Petrópolis: Vozes, 2014. 


\section{arevisto Observatório}

\section{ABSTRACT:}

This text presents a critical analysis of Enem's official dissemination campaigns in the years 2019 and 2020 amidst a scenario of political tensions between government and federal universities, also marked by the coronavirus pandemic. The study shows a partial representation, in the scope of Brazilian government advertising, sciences and higher education, characterized mainly by the overvaluation of courses in Health Sciences and courses traditionally valued by the labor market, such as Law and Engineering, in contrast to the relative invisibility of Human, Social Sciences and other areas of knowledge.

KEYWORDS: Communication; Science; Higher Education; Advertising; Government Advertising.

\section{RESUMEN:}

Este texto presenta un análisis critica de las campañas oficiales de difusión de Enem en los años 2019 y 2020 en medio de un escenario de tensiones políticas entre el gobierno y las universidades federales, también marcado por la pandemia de coronavirus. El estudio muestra una representación parcial, en el ámbito de la publicidad gubernamental brasileña, las ciencias y la educación superior, caracterizada principalmente por la sobrevaloración de los cursos en Ciencias de la Salud y cursos tradicionalmente valorados por el mercado laboral, como Derecho e Ingeniería, en contraste con la relativa invisibilidad de las ciencias humanas, sociales y otras áreas del conocimiento.

PALABRAS-CLAVES: Comunicación; Ciencias; Educación universitaria; Publicidad; Publicidad

gubernamental. 